\title{
-Original-
}

\section{Early Detection of Subclinical Anthracycline Cardiotoxicity on the Basis of QT Dispersion}

\author{
Yohko Uchikoba, Ryuji Fukazawa, Takashi Ohkubo, \\ Miho Maeda and Shunichi Ogawa \\ Department of Pediatrics, Graduate School of Medicine, Nippon Medical School
}

\begin{abstract}
Background: We examined whether dobutamine-stress QT dispersion (QTd) and heartrate corrected QT dispersion (QTcd) are useful for detecting subclinical anthracycline cardiotoxicity.

Methods: The subjects were10 control subjects and 37 patients divided into 4 groups according to cumulative anthracycline dose: non-anthracycline group (group N), 7 patients; low anthracycline cumulative dose group (group L), 8 patients $\left(<200 \mathrm{mg} / \mathrm{m}^{2}\right)$; medium anthracycline cumulative dose group (group M), 16 patients (200 to $<400 \mathrm{mg} / \mathrm{m}^{2}$ ); and high cumulative group (group H), 6 patients $\left(\geq 400 \mathrm{mg} / \mathrm{m}^{2}\right.$ ). Standard 12-lead electrocardiograms were recorded. QTd and QTcd were measured and calculated at rest and after administration of dobutamine at 5 or $30 \mu \mathrm{g} / \mathrm{kg} / \mathrm{min}$. We also estimated cardiac function and cardiac reserve function at rest and after administration of dobutamine at a dose of 5 or $30 \mu \mathrm{g} / \mathrm{kg} / \mathrm{min}$.

Results: At rest, QTd and QTcd were significantly greater in groups M and H. After administration of dobutamine at $30 \mu \mathrm{g} / \mathrm{kg} / \mathrm{min}$, QTd and QTcd were significantly greater in groups L, M, and $\mathrm{H}$. There was good correlation between QTd and the cumulative anthracycline dose; the correlation formula was $\mathrm{y}=0.051 \mathrm{x}+42.2(\mathrm{r}=0.81, \mathrm{p}<0.001)$. The cumulative anthracycline dose of $152.9 \mathrm{mg} / \mathrm{m}^{2}$, calculated from the correlation formula, was the cut-off for detection of electrophysiological cardiac abnormalities. Cardiac performance data at rest and dobutamine stress by echocardiography and pulsed Doppler echocardiography are less sensitive for detecting cardiac abnormalities than are QTd and QTcd.

Conclusions: Dobutamine-stress QTd and QTcd are useful for detecting anthracycline cardiotoxicity and subclinical cardiac abnormality at low cumulative anthracycline doses. We must be aware of the possibility of subclinical myocardial abnormalities in patients with a cumulative anthracycline dose of $\geq 150 \mathrm{mg} / \mathrm{m}^{2}$.
\end{abstract}

(J Nippon Med Sch 2010; 77: 234-243)

Key words: anthracycline cardiotoxicity, QT dispersion, heart-rate corrected QT dispersion, dobutamine, malignancy

Correspondence to Shunichi Ogawa, MD, Department of Pediatrics, Nippon Medical School, 1-1-5 Sendagi, Bunkyoku, Tokyo 113-8603, Japan

E-mail: boston@nms.ac.jp

Journal Website (http://www.nms.ac.jp/jnms/) 


\section{Introduction}

Anthracyclines, such as daunorubicin and doxorubicin, are highly effective antineoplastic agents in the treatment of solid tumors and hematological malignancies and form an important component of many antineoplastic chemotherapeutic regimens. Unfortunately, because anthracycline have acute and chronic effects on the myocardium, their use is limited by their cardiotoxicity. Acute anthracycline cardiotoxicity causes electrocardiographic abnormalities, such as sinus tachycardia, ST depression, and arrhythmias, during administration or several hours to several days after administration. However, most of the acute cardiotoxic effects of anthracycline are transient and reversible ${ }^{1}$. In contrast, chronic anthracycline cardiotoxicity causes irreversible cardiomyopathies and congestive heart failure that can restrict physical activity. The incidence of chronic anthracycline cardiotoxicity depends on the cumulative anthracycline dose administered. For example, the incidence of congestive heart failure is $0.01 \%$ to $0.27 \%$ for cumulative anthracycline doses $<550 \mathrm{mg} / \mathrm{m}^{2}$, and is $>30 \%$ for cumulative anthracycline doses $>550 \mathrm{mg} / \mathrm{m}^{2} 2.3$. Even at low doses, anthracyclines can cause subclinical myocardial damage with late fibrosis of the myocardium, as seen in biopsy specimens ${ }^{4}$. Therefore, effective monitoring of the cardiotoxic effects of anthracycline requires early assessment of both cardiac function and cardiac reserve function. This form of assessment may involve an exercise test. We previously performed exercise-stress echocardiography using a supine bicycle for asymptomatic patients receiving anthracycline therapy, and detected cardiac dysfunction even in children who received low-dose anthracycline therapy $\left(175 \mathrm{mg} / \mathrm{m}^{2}\right)^{5}$. For patients with a low tolerance for physical exercise, such as infants and small children, monitoring of cardiac function requires an alternative exercise test, such as a druginduced exercise test.

QT dispersion is defined as the difference between the maximum and minimum QT interval durations on 12-lead standard electrocardiography (ECG), and is considered to reflect local differences in the repolarization of the myocardium. QT dispersion, which reflects cardiac autonomic imbalance ${ }^{13}$, increases in various cardiac diseases, such as heart failure $^{6}$, cardiomyopathy ${ }^{7}$, ischemic heart disease ${ }^{8}$, hypertension $^{10}$, long-QT syndrome ${ }^{11,12}$, and after myocardial infarction ${ }^{9}$. QT dispersion is useful for determining prognosis in these diseases.

We hypothesize that dobutamine-stress QT dispersion (QTd) can be used to detect the ventricular spatial heterogeneity of repolarization, which is a sign of anthracycline cardiotoxicity at lower cumulative doses in long-term survivors after early-stage treatment for childhood malignancies. This study presents data to test this hypothesis.

\section{Patients and Methods}

\section{Subjects}

The subjects were 37 long-term survivors of childhood malignancies who underwent anthracycline therapy from 1998 through 2003 at our hospital (17 female and 20 male; present age range, 3 years 7 months to 28 years 3 months), and 10 volunteer healthy control subjects (control group; age range, $17-28$ years). Of the 37 patients, 24 had had acute lymphoblastic leukemia, 5 had had acute non-lymphoblastic leukemia, 2 had had Ewing sarcoma, 3 had had non-Hodgkin's lymphoma, 1 had had neuroblastoma, 1 had had Wilms tumor, and 1 had had Langerhans cell histiocytosis. The cumulative anthracycline doses of the patients ranged from 0 to $840 \mathrm{mg} / \mathrm{m}^{2}$ (Table 1). None of the patients had symptoms of congestive heart failure. The patients were divided into 4 groups according to their cumulative anthracycline dose, based on our previous findings $\mathrm{s}^{14}$. The groups were the nonanthracycline (group N, 7 patients); the low cumulative anthracycline dose group (group L, $<200$ $\mathrm{mg} / \mathrm{m}^{2} ; 8$ patients); the middle cumulative anthracycline dose group (group M, 200-<400 mg/ $\mathrm{m}^{2} ; 16$ patients); and the high cumulative anthracycline dose group (group $\mathrm{H}, \geq 400 \mathrm{mg} / \mathrm{m}^{2} ; 6$ patients) (Table 1). Informed consent was obtained for all subjects. 
Table 1 Patient characteristics

\begin{tabular}{|c|c|c|c|c|c|c|}
\hline $\begin{array}{l}\text { Case } \\
\text { No }\end{array}$ & Group & $\operatorname{sex}$ & $\begin{array}{l}\text { ATC cumulative dose } \\
\left(\mathrm{mg} / \mathrm{m}^{2}\right)\end{array}$ & age at test & diagnosis & $\begin{array}{l}\text { duration post } \\
\text { ATC therapy }\end{array}$ \\
\hline 1 & $\mathrm{~N}$ & $\mathrm{M}$ & 0 & $8 \mathrm{y} 11 \mathrm{~m}$ & ALL & $5 \mathrm{y} 7 \mathrm{mos}$ \\
\hline 2 & $\mathrm{~N}$ & $\mathrm{~F}$ & 0 & $15 \mathrm{y} 9 \mathrm{~m}$ & ALL & $6 \mathrm{y} 7 \mathrm{mos}$ \\
\hline 3 & $\mathrm{~N}$ & $\mathrm{M}$ & 0 & $12 \mathrm{y} 2 \mathrm{~m}$ & ALL & $5 \mathrm{y} 6 \mathrm{mos}$ \\
\hline 4 & $\mathrm{~N}$ & $\mathrm{M}$ & 0 & $16 \mathrm{y} 8 \mathrm{~m}$ & ALL & $4 \mathrm{y} 7 \mathrm{mos}$ \\
\hline 5 & $\mathrm{~N}$ & $\mathrm{M}$ & 0 & $14 \mathrm{y} 6 \mathrm{~m}$ & ALL & $4 y 8 \mathrm{mos}$ \\
\hline 6 & $\mathrm{~N}$ & $\mathrm{M}$ & 0 & $13 \mathrm{y} 2 \mathrm{~m}$ & ALL & $7 \mathrm{y} 2 \mathrm{mos}$ \\
\hline 7 & $\mathrm{~N}$ & $\mathrm{M}$ & 0 & $11 \mathrm{y} 2 \mathrm{~m}$ & ALL & $6 \mathrm{y} 2 \mathrm{mos}$ \\
\hline 8 & $\mathrm{~L}$ & $\mathrm{~F}$ & 80 (THP: 80) & $13 \mathrm{y} 2 \mathrm{~m}$ & ALL & $5 y 11 \mathrm{mos}$ \\
\hline 9 & $\mathrm{~L}$ & $\mathrm{M}$ & 100 (THP: 100) & $8 \mathrm{y} 11 \mathrm{~m}$ & ALL & $5 \mathrm{y} 7 \mathrm{mos}$ \\
\hline 10 & $\mathrm{~L}$ & $\mathrm{M}$ & 175 (ADM: 75, DXR: 100) & $28 \mathrm{y} 3 \mathrm{~m}$ & ALL & $10 \mathrm{y} 2 \mathrm{mos}$ \\
\hline 11 & $\mathrm{~L}$ & $\mathrm{~F}$ & 180 (ADM: 180) & $17 \mathrm{y} 9 \mathrm{~m}$ & ALL & $13 \mathrm{y} 0 \mathrm{mos}$ \\
\hline 12 & $\mathrm{~L}$ & $\mathrm{~F}$ & 140 (ADM: 140) & $3 \mathrm{y} 7 \mathrm{~m}$ & $\mathrm{LCH}$ & $1 \mathrm{y} 6 \mathrm{mos}$ \\
\hline 13 & $\mathrm{~L}$ & $\mathrm{M}$ & 130 (THP: 100, ACR: 30) & $12 \mathrm{y} 10 \mathrm{~m}$ & ALL & $8 \mathrm{y} 11 \mathrm{mos}$ \\
\hline 14 & $\mathrm{~L}$ & $\mathrm{M}$ & 100 (THP: 100) & $6 y 9 \mathrm{~m}$ & ALL & $3 \mathrm{y} 9 \mathrm{mos}$ \\
\hline 15 & $\mathrm{~L}$ & $\mathrm{M}$ & 170 (THP: 120, MIT: 20, ACR:30) & $18 \mathrm{y} 0 \mathrm{~m}$ & ALL & $4 y 8 \operatorname{mos}$ \\
\hline 16 & M & $\mathrm{M}$ & 200 (ADM: 200) & $9 \mathrm{y} 5 \mathrm{~m}$ & NHL & $2 \mathrm{y} 8 \mathrm{mos}$ \\
\hline 17 & M & $\mathrm{F}$ & 220 (THP: 220) & $11 \mathrm{y} 0 \mathrm{~m}$ & ALL & $2 \mathrm{y} 4 \mathrm{mos}$ \\
\hline 18 & M & $\mathrm{F}$ & 220 (IDAR: 120, THP: 20) & $11 \mathrm{y} 0 \mathrm{~m}$ & ALL & $4 \mathrm{y} 3 \mathrm{mos}$ \\
\hline 19 & $\mathrm{M}$ & $\mathrm{F}$ & 250 (DNR: 50, ADM: 200) & $7 \mathrm{y} 5 \mathrm{~m}$ & ALL & $3 \mathrm{y} 6 \mathrm{mos}$ \\
\hline 20 & $\mathrm{M}$ & $\mathrm{F}$ & 270 (ADM: 270) & $3 y 8 m$ & $\begin{array}{l}\text { Ewing } \\
\text { sarcoma }\end{array}$ & $1 \mathrm{y} 4 \mathrm{mos}$ \\
\hline 21 & M & $\mathrm{F}$ & 300 (ADM: 200, DNR: 100) & $7 \mathrm{y} 0 \mathrm{~m}$ & ALL & $4 y 2 \mathrm{mos}$ \\
\hline 22 & M & $\mathrm{F}$ & 300 (ADM: 300) & $9 y 5 \mathrm{~m}$ & $\begin{array}{l}\text { Wilms } \\
\text { tumor }\end{array}$ & $5 y 6 m o s$ \\
\hline 23 & $\mathrm{M}$ & $\mathrm{F}$ & 300 (ADM: 200, DNR: 100) & $8 \mathrm{y} 0 \mathrm{~m}$ & ALL & $4 y 6 \mathrm{mos}$ \\
\hline 24 & M & $\mathrm{F}$ & 305 (THP: 90, MIT: 35, ACR: 180) & $15 \mathrm{y} 11 \mathrm{~m}$ & ANLL & $4 \mathrm{y} 9 \mathrm{mos}$ \\
\hline 25 & M & $\mathrm{M}$ & 330 (DNR: 180, ACR: 150) & $18 \mathrm{y} 4 \mathrm{~m}$ & ALL & $12 \mathrm{y} 7 \mathrm{mos}$ \\
\hline 26 & M & M & 330 (DNR: 180, ACR: 150) & $15 \mathrm{y} 5 \mathrm{~m}$ & ALL & $11 \mathrm{y} 10 \mathrm{mos}$ \\
\hline 27 & M & $\mathrm{F}$ & 360 (ADM: 360) & $8 \mathrm{y} 10 \mathrm{~m}$ & $\begin{array}{l}\text { Ewing } \\
\text { sarcoma }\end{array}$ & $3 y 8 \operatorname{mos}$ \\
\hline 28 & M & $\mathrm{F}$ & 220 (THP: 220) & $7 \mathrm{y} 0 \mathrm{~m}$ & ALL & $3 \mathrm{y} 2 \mathrm{mos}$ \\
\hline 29 & M & $\mathrm{M}$ & 232 (THP: 100, IDAR: 132) & $15 \mathrm{y} 0 \mathrm{~m}$ & ALL & $3 y 6 m o s$ \\
\hline 30 & M & $\mathrm{M}$ & 300 (ADM: 200, DNR: 100) & $16 \mathrm{y} 9 \mathrm{~m}$ & ALL & $3 y 5 m o s$ \\
\hline 31 & M & $\mathrm{F}$ & 375 (THP: 375) & $13 \mathrm{y} 0 \mathrm{~m}$ & ANLL & $9 y 1 \mathrm{mos}$ \\
\hline 32 & $\mathrm{H}$ & $\mathrm{M}$ & 420 (ADM: 420) & $13 \mathrm{y} 3 \mathrm{~m}$ & Neuroblastoma & $8 \mathrm{y} 4 \mathrm{mos}$ \\
\hline 33 & $\mathrm{H}$ & $\mathrm{M}$ & 490 (ADM: 50, EPR: 440) & $9 y 6 m$ & NHL & $4 y 2 \mathrm{mos}$ \\
\hline 34 & $\mathrm{H}$ & $\mathrm{F}$ & 540 (ADM: 360, THP: 180) & $18 \mathrm{y} 4 \mathrm{~m}$ & ANLL & $9 \mathrm{y} 2 \mathrm{mos}$ \\
\hline 35 & $\mathrm{H}$ & $\mathrm{M}$ & 600 (DNR: 60, THP: 360, ACR: 180) & $18 \mathrm{y} 0 \mathrm{~m}$ & ANLL & $4 y 6 \mathrm{mos}$ \\
\hline 36 & $\mathrm{H}$ & $\mathrm{M}$ & 840 (DNR: 140, THP: 720) & $6 y 8 m$ & NHL & $2 \mathrm{y} 3 \mathrm{mos}$ \\
\hline 37 & $\mathrm{H}$ & $\mathrm{F}$ & 460 (ADM: 360, THP: 100) & $16 \mathrm{y} 8 \mathrm{~m}$ & ANLL & $8 y 10 \mathrm{mos}$ \\
\hline
\end{tabular}

M: male, F: female, ATC: anthracycline, ALL: acute lymphoblastic leukemia, ANLL: acute non-lymphoblastic leukemia, LCH: Langerhans cell histiocytosis, NHL: non-Hodgikin's lymphoma. ADM: doxorubicin, DNR: daunorubicin, IDAR: idarubicin, TPH: pirarubicin, MIT: mitoxantrone, ACR: aclarubicin

\section{Dobutamine Stress Protocol}

Dobutamine was infused at an initial rate of $5 \mu \mathrm{g} /$ $\mathrm{kg} / \mathrm{min}$ for 3 minutes, and the infusion rate was increased by $5 \mu \mathrm{g} / \mathrm{kg} / \mathrm{min}$ every 3 minutes to a maximum of $30 \mu \mathrm{g} / \mathrm{kg} / \mathrm{min}$. Infants and small children were sedated during the dobutamine stress test. Administration of dobutamine was prematurely stopped under the following conditions: if the subject experienced intolerable chest pain, palpitations, headache, nausea, or other symptoms; if the systolic blood pressure rose to $>200 \mathrm{mmHg}$; if frequent episodes of ventricular arrhythmia were observed; or if sustained ventricular tachycardia was observed. Throughout this protocol, continuous ECG monitoring was performed. Heart rate and blood 
pressure were recorded at baseline and after each stage of dobutamine infusion, and the double product (DP: defined as heart rate multiplied by systolic pressure) was calculated as an index of stress volume.

\section{ECG and QT Analysis}

Standard 12-lead ECGs were recorded at a paper speed of $25 \mathrm{~mm} / \mathrm{s}$ for each study subject in the supine position with Cardio Multi FDX-4520 (Fukuda Denshi, Tokyo, Japan). Subjects were required to lie supine for 5 minutes for stabilization before ECGs were recorded. All ECGs were sampled at $250 \mathrm{~Hz}$ with simultaneous 12-lead recordings, and digitized data were saved to a floppy disk for automated analysis. For each ECG, QT intervals in each lead were automatically calculated without manual modification of the computerized recognition of the T-wave offset. The T-wave offset was detected as the intersect of the T-P isoelectric baseline with the least-squares-fit line around the target to the T-wave downslope. The heart-rate corrected QT (QTc) was calculated using the Bazett formula: $\mathrm{QTc}=\mathrm{QT} / \sqrt{ } \mathrm{RR}$ interval. The QT intervals were measured from the QRS complex to the end of the $\mathrm{T}$ wave. If a $\mathrm{U}$ wave was present, the $\mathrm{T}$ wave offset was defined as the nadir between the $\mathrm{T}$ and $\mathrm{U}$ waves. If the $\mathrm{T}$ wave offset could not be identified, the lead was excluded from analysis. The QTd, which is defined as the difference between the maximum and minimum QT intervals, was derived for each recording. The heartrate corrected QTd (QTcd) was calculated with the Bazett formula.

\section{Echocardiography and Pulsed Doppler Echocardiography}

After 5 minutes of rest, systolic and diastolic blood pressures were measured in the upper limb by means of a manual sphygmomanometer with a 5-, 9-, or 14-cm cuff. Echocardiography and pulsed Doppler echocardiography were performed with a HewlettPackard SONOS-2500 (Hewlett-Packard, Palo Alto, CA, USA) with a 5- or $3.5-\mathrm{MHz}$ transducer. Phonocardiograms, indirect carotid pulse tracing, and ECGs were simultaneously recorded at a paper speed of $50 \mathrm{~mm} / \mathrm{s}$. The 2-dimensional echocardiogram was recorded in the standard left ventricular (LV) short axis view at the level of the chordae tendineae, with the M-mode cursor angled through the center of the LV cavity. We measured the LV end-systolic and end-diastolic dimensions (LVDs and LVDd), and the end-systolic and enddiastolic posterior wall thickness (PWTs, PWTd). We calculated the following indices: 1) LV ejection fraction $(\mathrm{EF})=\left(\operatorname{LVDd}^{3}-\mathrm{LVDs}^{3}\right) / \mathrm{LVDd}^{3}$, as an index of cardiac performance; 2) end-systolic wall stress $(\mathrm{ESS})=\mathrm{P} \times \mathrm{LVDs} \times 1.35 / 4 \times \mathrm{PWTs} \times(1+\mathrm{PWTs} /$ LVDs $)^{15}$, where $\mathrm{P}$ is the $\mathrm{LV}$ end-systolic pressure calculated from the measured upper limb systolic blood pressure $(\mathrm{P}=0.66 \times$ systolic blood pressure + $\left.13.5^{16}\right)$, as an index of LV after-load; 3) percentage LV posterior wall thickening $(\% \mathrm{PWT})=100 \times(\mathrm{PWT}-$ PWTd)/PWTd, as an index of the rate of change of LV wall thickness. Pulsed Doppler echocardiograms were obtained in the left parasternal 4-chamber view. The sample volumes were placed on the mitral valve annulus, and the angle between the Doppler beam and the presumed mitral flow vectors was kept as small as possible. We measured the maximum early filling peak velocity (E) and the atrial contraction peak velocity (A) from the LV transmitral flow wave recordings, and calculated E/ $\mathrm{A}$ as an index of diastolic function.

The investigators who interpreted the QT dispersion, M-mode echocardiograms, and pulse Doppler echocardiograms were blinded to the clinical data.

\section{Statistical Analysis}

Differences among the groups were analyzed at each stage with one-way analysis of variance (Scheffe's method). Differences with a probability value of $\mathrm{p}<0.05$ were considered statistically significant.

\section{Results}

Clinical Data of the Patients and Control Subjects

There were no significant differences in the levels of hemoglobin or electrolytes between any of the groups (Table 2). 
Table 2 Hemblobin and electrolytes

\begin{tabular}{ccccc}
\hline & $\begin{array}{c}\mathrm{Hb} \\
(\mathrm{g} / \mathrm{dL})\end{array}$ & $\begin{array}{c}\mathrm{Na}^{+} \\
(\mathrm{mEq} / \mathrm{L})\end{array}$ & $\begin{array}{c}\mathrm{K}^{+} \\
(\mathrm{mEq} / \mathrm{L})\end{array}$ & $\begin{array}{c}\mathrm{Ca}^{2+} \\
(\mathrm{mg} / \mathrm{dL})\end{array}$ \\
\hline control & $13.5 \pm 0.8$ & $141.4 \pm 4.3$ & $4.3 \pm 0.3$ & $9.4 \pm 0.2$ \\
$\mathrm{~N}$ & $12.6 \pm 0.6$ & $139.8 \pm 3.6$ & $4.2 \pm 0.2$ & $9.6 \pm 0.3$ \\
$\mathrm{~L}$ & $11.9 \pm 0.9$ & $140.2 \pm 2.9$ & $4.5 \pm 0.3$ & $9.4 \pm 0.2$ \\
$\mathrm{M}$ & $12.6 \pm 0.8$ & $142.3 \pm 4.9$ & $4.2 \pm 0.2$ & $9.7 \pm 0.4$ \\
$\mathrm{H}$ & $12.1 \pm 0.7$ & $140.6 \pm 5.2$ & $4.1 \pm 0.2$ & $9.5 \pm 0.2$ \\
\hline
\end{tabular}

Hb: hemoglobin

\section{Hemodynamic Changes before and after Dobutamine Stress}

No subjects showed any symptoms or arrhythmias in response to dobutamine administration, and all subjects were a given the full dobutamine dose of $30 \mu \mathrm{g} / \mathrm{kg} / \mathrm{min}$. In each group, the heart rate and systolic blood pressure increased significantly from those at rest to those after administration of dobutamine at $30 \mu \mathrm{g} / \mathrm{kg} / \mathrm{min}$. There were no significant differences between any of the groups at rest or after administration of dobutamine at $30 \mu \mathrm{g} / \mathrm{kg} / \mathrm{min}$. In all groups, DP was greater after administration of dobutamine at $30 \mu \mathrm{g} /$ $\mathrm{kg} / \mathrm{min}$ than at rest or after low-dose dobutamine administration. In all groups, the mean DP increased significantly up to 20,000 , which is thought to be a practical exercise volume after administration of dobutamine at $30 \mu \mathrm{g} / \mathrm{kg} / \mathrm{min}$ (Table 3).

QTd, QTed Values at Rest, and after Low- and

\section{High-dose Dobutamine Stress}

We could not identify the $\mathrm{T}$ wave offset in 4 patients at high-dose dobutamine stress, which included leads $\mathrm{I}$ and $\mathrm{a} \mathrm{V}_{\mathrm{L}}$ in 2 patients from groups $\mathrm{M}$ and $H$, lead $a V_{L}$ in 1 patient from group $M$, and lead $V_{1}$ in 1 patient from group L. We examined whether sex affected QTd and found that QTd is not sexdependent (male QTd: $44.5 \pm 3.9$, female QTd: $46.3 \pm$ 4.1). At rest, QTd and QTcd were significantly greater in groups $\mathrm{M}$ and $\mathrm{H}$ (group $\mathrm{M}$ : $51.3 \pm 4.5$, 52.8 \pm 3.6 , group $\mathrm{H}: 52.1 \pm 4.1,54.0 \pm 3.4$ ) than in the other 3 groups or in healthy control subjects $(\mathrm{p}<$ 0.05). This finding indicates that inhomogeneity of ventricular repolarization occurred even at rest in patients who received an anthracycline dose of $\geq 200 \mathrm{mg} / \mathrm{m}^{2}$. When the cut-off value for normal QTd was set at $<50$ milliseconds ${ }^{17.18}, 68.8 \%$ (11 of 16) of the patients in group $\mathrm{M}$ and $83.3 \%$ (5 of 6 ) of patients in group $\mathrm{H}$ had an abnormal QTd. After administration of dobutamine at $5 \mu \mathrm{g} / \mathrm{kg} / \mathrm{min}$, the results were the same as those at rest. After administration of dobutamine at $30 \mu \mathrm{g} / \mathrm{kg} / \mathrm{min}$, QTd and QTcd were significantly greater in patients from group L (56.5 $\pm 4.8,79.6 \pm 8.4)$, group M $(61.2 \pm$ $6.4,81.3 \pm 8.5)$, or group $\mathrm{H}(64.3 \pm 7.7,83.0 \pm 10.5)$ than in the other 2 groups or in healthy control subjects $(\mathrm{p}<0.05)$ (Table 4$)$. With a QTd cut-off value of $<50$ milliseconds, 5 of the 8 patients $(62.5 \%)$ in group L, 15 of the 16 patients (93.8\%) in group M, and all 6 patients in group $\mathrm{H}$ had an abnormal QTd. On the other hand, there were no significant differences in QTd or QTcd between group N and the control subjects at rest or after administration of dobutamine at 5 or $30 \mu \mathrm{g} / \mathrm{kg} / \mathrm{min}$.

\section{Correlation between Cumulative Anthracycline} Dose and QTd at Rest and after Dobutamine Stress at $30 \mu \mathrm{g} / \mathrm{kg} / \mathrm{min}$.

We tested the correlation between cumulative anthracycline dose and QTd after dobutamine stress at $30 \mu \mathrm{g} / \mathrm{kg} / \mathrm{min}$, and found a good correlation using the following correlation formula: $\mathrm{y}=0.051 \mathrm{x}+42.2$ $(\mathrm{r}=0.81, \mathrm{p}<0.001)$ (Fig. 1). This correlation suggests that QTd was worse at the highest cumulative anthracycline dose. The cut-off value for detection of abnormal cardiac reserve function was at a cumulative anthracycline dose of $152.9 \mathrm{mg} / \mathrm{m}^{2}$, which was calculated using the correlation formula between QTd and cumulative anthracycline dose. The sensitivity and specificity for detection of anthracycline cardiotoxicity based on our findings of abnormal QTd ( $\geq 50$ milliseconds) after high-dose dobutamine stress in patients with a cumulative anthracycline dose of $>150 \mathrm{mg} / \mathrm{m}^{2}$ were $96.0 \%$ and $83.3 \%$, respectively. This finding shows that patients receiving a cumulative dose of anthracycline of $150 \mathrm{mg} / \mathrm{m}^{2}$ or more display subclinical electrophysiological anthracycline cardiotoxicity. Thus, QTd is a reliable predictor of anthracycline cardiotoxicity in patients treated with anthracyclines, and subclinical myocardial 
Table 3 Cardiovascular hemodynamic changes before and after dobutamine stress

\begin{tabular}{|c|c|c|c|c|c|c|c|c|c|}
\hline group & HR rest & $\begin{array}{c}\text { HR } \\
\text { DOB-5 }\end{array}$ & $\begin{array}{c}\text { HR } \\
\text { DOB-30 }\end{array}$ & $\begin{array}{l}\text { sys BP } \\
\text { rest }\end{array}$ & $\begin{array}{l}\text { sys BP } \\
\text { DOB-5 }\end{array}$ & $\begin{array}{l}\text { sys BP } \\
\text { DOB-30 }\end{array}$ & DP rest & DP DOB-5 & DP DOB-30 \\
\hline control & $71.6 \pm 12.2$ & $3 \pm 16.3$ & $121.7 \pm 20.8$ & 109.1 & 123.8 & 166.3 & 7 , & 679 & 126 \\
\hline $\mathrm{N}$ & $65.0 \pm 11.2$ & $67.1 \pm 10.2$ & $121.3 \pm 9.1$ & $107.1 \pm 6.7$ & $124.3 \pm 10.4$ & $166.2 \pm 14.0$ & 7,608 & 9,563 & 21,4 \\
\hline $\mathrm{L}$ & $73.1 \pm 16.6$ & $72.0 \pm 12.3$ & $120.4 \pm 28.9$ & $107.2 \pm 12.0$ & $122.5 \pm 12.3$ & $163.2 \pm 17.1$ & 7,803 & 9,457 & 21,7 \\
\hline M & $73.4 \pm 11.1$ & $72.6 \pm 12.6$ & $125.2 \pm 19.8$ & $100.9 \pm 12.6$ & $125.4 \pm 14.7$ & $150.5 \pm 18.8$ & $8,021 \pm 896$ & $9,138 \pm 1,236$ & $22,105 \pm 1,203$ \\
\hline $\mathrm{H}$ & $68.8 \pm 9.9$ & $83.5 \pm 36.4$ & $137.0 \pm 15.4$ & $100.5 \pm 10.5$ & $123.0 \pm 5.3$ & $154.0 \pm 18.6$ & $7,996 \pm 913$ & $10,166 \pm 2,076$ & $21,326 \pm 1,026$ \\
\hline
\end{tabular}

HR: heart rate, DOB: dobutamine, sys BP: systolic blood pressure, DP: double product

Table 4 QTd and QTcd values at rest, after DOB $5 \mu \mathrm{g} / \mathrm{kg} /$ minute and $30 \mu \mathrm{g} / \mathrm{kg} /$ minute stress

\begin{tabular}{ccccccc}
\hline & $\begin{array}{c}\text { QTd rest } \\
(\mathrm{msec})\end{array}$ & $\begin{array}{c}\text { QTd DOB-5 } \\
(\mathrm{msec})\end{array}$ & $\begin{array}{c}\text { QTd DOB-30 } \\
(\mathrm{msec})\end{array}$ & $\begin{array}{c}\text { QTcd rest } \\
(\mathrm{msec})\end{array}$ & $\begin{array}{c}\text { QTcd DOB-5 } \\
(\mathrm{msec})\end{array}$ & $\begin{array}{c}\text { QTcd DOB-30 } \\
(\mathrm{mseec})\end{array}$ \\
\hline control & $37.1 \pm 9.0$ & $41.1 \pm 7.8$ & $42.6 \pm 7.9$ & $44.1 \pm 10.9$ & $46.8 \pm 13.1$ & $57.8 \pm 9.8$ \\
N & $38.7 \pm 3.6$ & $39.2 \pm 4.6$ & $41.2 \pm 4.6$ & $44.7 \pm 7.8$ & $47.2 \pm 5.6$ & $58.3 \pm 7.9$ \\
L & $39.1 \pm 4.6$ & $41.1 \pm 4.2$ & $56.5 \pm 4.8^{*}$ & $43.1 \pm 6.0$ & $48.3 \pm 7.1$ & $79.6 \pm 8.4^{*}$ \\
M & $51.3 \pm 4.5^{*}$ & $51.7 \pm 5.3^{*}$ & $61.2 \pm 6.4^{*}$ & $52.8 \pm 3.6^{*}$ & $56.6 \pm 6.5^{*}$ & $81.3 \pm 8.5^{*}$ \\
H & $52.1 \pm 4.1^{*}$ & $52.2 \pm 6.8^{*}$ & $64.3 \pm 7.7^{*}$ & $54.0 \pm 3.4^{*}$ & $57.3 \pm 8.4^{*}$ & $83.0 \pm 10.5^{*}$ \\
\hline
\end{tabular}

QTd: QT dispersion, QTcd: corrected QT dispersion * $\mathrm{p}<0.05$ vs. other groups

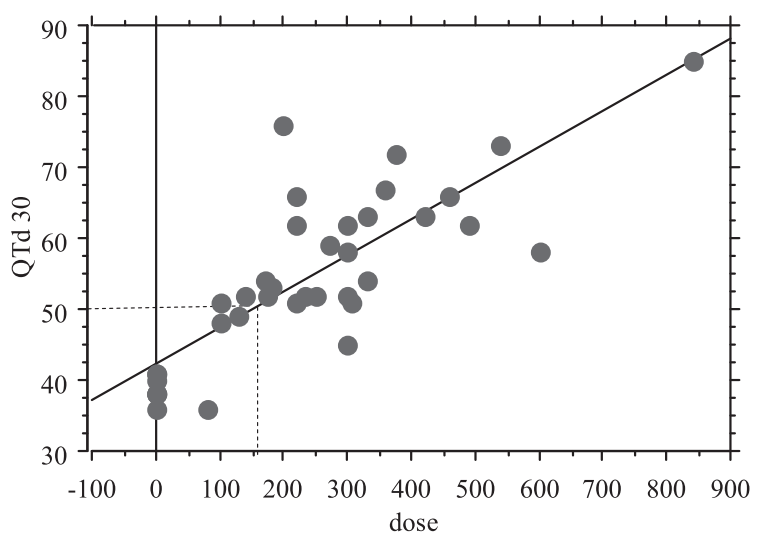

Fig. 1 Correlation between cumulative anthracycline dose and QT dispersion after dobutamine stress at $30 \mu \mathrm{g} / \mathrm{kg} / \mathrm{min}$.

The $\mathrm{Y}$ axis shows QT dispersion after dobutamine stress at $30 \mu \mathrm{g} / \mathrm{kg} / \mathrm{min}$, and the $\mathrm{X}$ axis shows the cumulative anthracycline dose. There was a good correlation between these indices, with a correlation formula of $\mathrm{y}=0.051 \mathrm{x}+42.2(\mathrm{r}=0.81, \mathrm{p}<0.001)$.

abnormalities can develop in patients receiving a cumulative anthracycline dose of $\geq 150 \mathrm{mg} / \mathrm{m}^{2}$. On the other hand, we found a good correlation between anthracycline dose and QTd at rest using the following correlation formula: $\mathrm{y}=0.04 \mathrm{x}+28.9(\mathrm{r}=$ $0.78, \mathrm{p}<0.001)$. When the abnormal value was 50 milliseconds, the cut-off value for detection of cardiotoxicity was a cumulative anthracycline dose of $526.3 \mathrm{mg} / \mathrm{m}^{2}$, which seems far less sensitive for detecting anthracycline cardiotoxicity.

\section{EF, ESS, E/A, and \%PWT at Rest and after}

\section{Low- and High-dose Dobutamine Stress}

We could perform cardiac performance tests for 7 of 10 control subjects, all patients of group N, 7 of 8 patients of group L, 14 of 16 patients of group M, and all patients of group $\mathrm{H}$. At rest and after dobutamine stress at $5 \mu \mathrm{g} / \mathrm{kg} / \mathrm{min}, \mathrm{E} / \mathrm{A}$ and $\% \mathrm{PWT}$ were significantly lower in group $\mathrm{H}$ than in the other 4 groups. After dobutamine stress at $30 \mu \mathrm{g} /$ $\mathrm{kg} / \mathrm{min}$, groups $\mathrm{M}$ and $\mathrm{H}$ showed $\mathrm{ESS}, \mathrm{E} / \mathrm{A}$, and $\%$ PWT values that were significantly different from those of the other 3 groups. Increases in ESS and decreases in \%PWT were due to reduced endsystolic LV wall thickness (data not shown), and decreases in $\mathrm{E} / \mathrm{A}$ indicated reduced diastolic function. These results suggest that patients with a cumulative $\mathrm{m}^{2}$ dose of $\geq 400 \mathrm{mg} / \mathrm{m}^{2}$ had subclinical decreases in LV muscle volume and subclinical increases in LV wall stiffness. On the other hand, there were no significant differences in $\mathrm{EF}$ among the 5 groups at rest, after dobutamine stress at 5 $\mu \mathrm{g} / \mathrm{kg} / \mathrm{min}$, or after dobutamine stress at $30 \mu \mathrm{g} / \mathrm{kg} /$ 
Table 5-1 EF and ESS values at rest, after DOB $5 \mu \mathrm{g} / \mathrm{kg} /$ minute and $30 \mu \mathrm{g} / \mathrm{kg} /$ minute stress

\begin{tabular}{ccccccc}
\hline & EF rest & EF DOB-5 & EF DOB-30 & ESS rest & ESS DOB-5 & ESS DOB-30 \\
\hline control & $64.1 \pm 6.0$ & $69.7 \pm 9.6$ & $79.0 \pm 4.7$ & $55.1 \pm 7.0$ & $54.2 \pm 3.2$ & $51.1 \pm 2.5$ \\
N & $68.3 \pm 3.6$ & $74.9 \pm 3.6$ & $80.9 \pm 4.8$ & $55.8 \pm 6.3$ & $55.3 \pm 2.9$ & $52.3 \pm 3.1$ \\
L & $62.5 \pm 9.1$ & $70.4 \pm 8.7$ & $78.0 \pm 7.7$ & $56.6 \pm 2.1$ & $56.4 \pm 9.1$ & $51.5 \pm 2.1$ \\
M & $61.6 \pm 8.3$ & $67.0 \pm 8.4$ & $75.8 \pm 10.8$ & $54.7 \pm 8.7$ & $56.2 \pm 8.6$ & $63.9 \pm 7.1^{*}$ \\
H & $58.7 \pm 9.5$ & $68.7 \pm 4.9$ & $81.0 \pm 1.0$ & $58.8 \pm 14.8$ & $61.6 \pm 17.5$ & $62.2 \pm 13.1^{*}$ \\
\hline
\end{tabular}

EF: ejection fraction, ESS: end-systolic left ventricular wall stress, ${ }^{*} \mathrm{p}<0.05$ vs. other groups

Table 5-2 E/A and \%PWT values at rest, after DOB $5 \mu \mathrm{g} / \mathrm{kg} /$ minute and $30 \mu \mathrm{g} / \mathrm{kg} /$ minute stress

\begin{tabular}{ccccccc}
\hline & E/A rest & E/A DOB-5 & E/A DOB-30 & \%PWT rest & \%PWT DOB-5 & \%PWT DOB-30 \\
\hline control & $2.0 \pm 0.1$ & $2.2 \pm 0.1$ & $1.5 \pm 0.1$ & $96.2 \pm 1.6$ & $115.3 \pm 5.6$ & $132.7 \pm 5.7$ \\
N & $2.1 \pm 0.2$ & $2.3 \pm 0.1$ & $1.4 \pm 0.1$ & $94.8 \pm 4.3$ & $118.6 \pm 7.6$ & $134.8 \pm 4.9$ \\
L & $2.1 \pm 0.1$ & $2.3 \pm 0.2$ & $1.6 \pm 0.2$ & $91.2 \pm 4.6$ & $109.1 \pm 9.5$ & $135.8 \pm 26.3$ \\
M & $2.0 \pm 0.2$ & $2.1 \pm 0.3$ & $1.2 \pm 0.1^{*}$ & $91.7 \pm 3.2$ & $112.4 \pm 6.1$ & $96.2 \pm 3.8^{*}$ \\
H & $1.7 \pm 0.2^{*}$ & $1.8 \pm 0.2^{*}$ & $1.0 \pm 0.1^{*}$ & $68.9 \pm 6.1^{*}$ & $92.4 \pm 11.2^{*}$ & $92.2 \pm 5.5^{*}$ \\
\hline
\end{tabular}

E/A: ratio of the maximum early filling peak velocity (E) and the atrial contraction peak velocity (A), \%PW: percentage left ventricular posterior wall thickness ${ }^{*} \mathrm{p}<0.05$ vs. other groups

min. These findings suggest that even the highest cumulative $\mathrm{m}^{2}$ doses in the patients did not reduce LV systolic function (Table 5-1, 5-2). These findings using 2-dimensional echocardiography and pulse Doppler echocardiography are similar to the findings we obtained in our previous study ${ }^{14}$.

\section{Discussion}

Late cardiotoxic effects of anthracycline are an increasing problem for survivors of childhood cancer. Anthracycline-induced congestive heart failure is a dose-dependent phenomenon. Reported incidences of anthracycline-induced congestive heart failure range from $>5 \%$ (cumulative adriamycin dose, 501 to 550 $\mathrm{mg} / \mathrm{m}^{2}$ ) to $>30 \%$ (cumulative adriamycin dose, $>601$ $\left.\mathrm{mg} / \mathrm{m}^{2}\right)^{19}$. In a long-term follow-up study, patients who had no symptoms of cardiotoxicity at the time of complete remission of cancer after adriamycin therapy had an unusually high incidence of cardiovascular complications typical of adriamycin cardiomyopathy over the subsequent 4 to 20 years ${ }^{20}$. Thus, it is important to find ways to avoid or minimize the cardiotoxic side effects of anthracycline in the treatment of cancer.

Several effects of anthracycline which may play critical roles in the pathogenesis of anthracycline cardiomyopathy have been described. Most studies support the view that an increase in oxidative stress (evidenced by increases in free radicals and lipid peroxidation and decreases in antioxidants and sulfhydryl groups) plays an important role in the pathogenesis of anthracycline cardiomyopathy ${ }^{2.22}$. The unique sensitivity of the myocardium to anthracyclines may be due to the low levels of catalase and superoxide dismutase in cardiac myocytes ${ }^{23}$.

The main features of cardiac biopsies from anthracycline-treated patients are cytoplasmic vacuolization due to dilation of the sarcotubules and loss of myofibrils ${ }^{1924}$. In patients who received a high dose $\left(455-500 \mathrm{mg} / \mathrm{m}^{2}\right)$ of daunomycin, cardiac biopsies exhibited degenerative, atrophic, and lytic lesions in cardiac muscle cells, and interstitial edema and fibrosis ${ }^{23}$. These histological abnormalities could strongly affect myocardial action potentials and cellto-cell conduction, and lead to inhomogeneity of ventricular depolarization and repolarization. Previously, we reported that anthracycline-treated patients exhibited abnormal ventricular depolarization, as revealed by signal-averaged electrocardiography ${ }^{25}$. However, there have been no other reports of abnormalities of ventricular repolarization in anthracycline-treated patients. QT 
dispersion is defined as the difference between the maximum and minimum QT interval durations on a 12-lead standard ECG and is considered to reflect local differences in repolarization of the myocardium. In the present study, at rest, when the cut-off value for normal QTd was set at $<50$ milliseconds ${ }^{17.18}$, the QTd was abnormal in $68.8 \%$ of the patients with a cumulative anthracycline dose of $\geq 200 \mathrm{mg} / \mathrm{m}^{2}$ and in $83.3 \%$ of the patients with a cumulative anthracycline dose of $\geq 400 \mathrm{mg} / \mathrm{m}^{2}$. An abnormal increase in QT dispersion could be caused by inhomogeneity of ventricular repolarization. The QTc was prolonged at rest by more than 450 milliseconds in only 5 of the present cases. The QTc may be less sensitive as an index of anthracycline cardiotoxicity at rest than are the QTd data. On the other hand, in the present study, 2-dimensional echocardiography showed that only patients with a cumulative anthracycline dose of $\geq 400 \mathrm{mg} / \mathrm{m}^{2}$ had a significantly reduced $\mathrm{LV}$ cardiac muscle volume at rest, which is consistent with our previous finding $\mathrm{s}^{25}$. It appears likely that decreased numbers of cardiac myocytes and increased interstitial edema and fibrosis leads not only to reduced ventricular cardiac volume but also to abnormal microelectrical findings. Our findings show that for patients with a cumulative anthracycline dose of $\geq 200 \mathrm{mg} / \mathrm{m}^{2}$, electrical findings at rest indicates cardiotoxic effects (morphological changes in ventricular myocardium) that require intervention.

Dobutamine is a synthetic catecholamine $\alpha 1, \beta 1$ and $\beta 2$ with mimetic activity. Dobutamine has inotropic effects at low doses $(5-10 \mu \mathrm{g} / \mathrm{kg} / \mathrm{min})$ and causes increased heart rate, blood pressure, and coronary vasodilation at high doses ( $>20 \mu \mathrm{g} / \mathrm{kg} / \mathrm{min})$. Thease changes lead to increased oxygen consumption in the myocardium and increase the inhomogeneity of ventricular myocytes at moderate doses $(>10 \mu \mathrm{g} / \mathrm{kg} / \mathrm{min})^{26}$. These findings suggest that the inhomogeneity of ventricular repolarization can be increased in cardiac myocytes exposed to anthracyclines. In this study, we evaluated myocardial reserve function as an indicator of cardiotoxicity, by performing electrophysiological and morphological evaluations under dobutamineinduced stress. After dobutamine stress at $30 \mu \mathrm{g} /$ $\mathrm{kg} / \mathrm{min}$, patients with a very low cumulative anthracycline dose (anthracycline dose $\geq 80 \mathrm{mg} / \mathrm{m}^{2}$ ) had significantly greater QTd and QTcd than did control subjects or patients who had not received an anthracycline. With the cut-off value of $>50$ milliseconds, an abnormal QTd was found in 62.5\% of patients with a cumulative anthracycline dose of 80 to $<200 \mathrm{mg} / \mathrm{m}^{2}, 93.8 \%$ of patients with a cumulative anthracycline dose of 200 to $<400 \mathrm{mg} / \mathrm{m}^{2}$, and $100 \%$ of patients with a cumulative anthracycline dose of $\geq 400 \mathrm{mg} / \mathrm{m}^{2}$. We also evaluated cardiotoxicity by examining cardiac muscle performance under dobutamine stress using 2-dimensional echocardiography and pulsed Doppler echocardiography. The values for ESS, E/A, and \%PWT that we obtained were consistent with our previous findings ${ }^{25}$, yet were much less sensitive than were the QTd and QTcd data that we obtained in the present study. Because these indices are calculated from changes in LV wall motion on echocardiograms, detectable changes in wall motion must require much higher cumulative doses than the electrophysiological changes detected on the basis of QT dispersion. Data from 2-dimensional echocardiography and pulsed Doppler echocardiography is more difficult to evaluate than are data from 12-lead ECG. Moreover, whereas sedation may be needed for infants and small children when they undergo echocardiography, there is no need for sedation to perform 12-lead ECG. Thus, in terms of ease of use, QTd and QTcd have clear advantages over ESS, E/A, and \%PWT as indices for detecting anthracycline cardiotoxicity that manifests as abnormal cardiac reserve function.

In the present study, there was little difference between QTd and QTcd. Some earlier studies have found no evidence that QT dispersion requires the same type of heart rate correction as the duration of the QT interval ${ }^{27,28}$. Also, clear criteria have recently been established for detecting abnormal QTd based on electrophysiological findings ${ }^{17.18}$, whereas no precise value for detecting abnormal QTcd has been established. Moreover, assessing QTd is much easier than assessing QTcd. Thus, QTd has an advantage over QTcd as an index for detecting abnormal ventricular inhomogeneity. 
In the present study, we also assessed the correlation between cumulative anthracycline dose and QTd after dobutamine stress at $30 \mu \mathrm{g} / \mathrm{kg} / \mathrm{min}$. We found a good correlation between those 2 variables when using the correlation formula: $y=$ $0.051 \mathrm{x}+42.2(\mathrm{r}=0.81, \mathrm{p}<0.001)$ (Fig. 1). With this formula, we determined that a cumulative anthracycline dose of $152.9 \mathrm{mg} / \mathrm{m}^{2}$ was the cut-off for detecting abnormal cardiac reserve function. Based on these results, the sensitivity and specificity for detecting anthracycline cardiotoxicity as indicated by abnormal QTd after high-dose dobutamine stress ( $\geq 50$ milliseconds) in patients with a cumulative anthracycline dose of $>150 \mathrm{mg} / \mathrm{m}^{2}$ were $96.0 \%$ and $83.3 \%$, respectively. This finding suggests that the physicians of patients with a cumulative anthracycline dose of $>150 \mathrm{mg} / \mathrm{m}^{2}$ should consider the possibility of decreased cardiac reserve function. QTd appears to be a useful index for detecting cumulative anthracycline cardiotoxicity.

Previously, we reported that anthracycline-treated patients exhibit abnormal ventricular depolarization, as revealed by signal-averaged ECG (SAE). However, the microvolt electrophysiological changes detected with SAE require several criteria that are dependent on method and age. Because measurement of QTd is a convenient and independent of age and $\operatorname{sex}^{29}$, it is, therefore, a much better method than SAE for detecting anthracycline cardiotoxicity.

Finally, we did not evaluate the reproducibility of QTd in this study. Many papers have reported that the reproducibility of QT dispersion is significantly poorer than the reproducibility of the QT interval itself. Nevertheless, despite this poor reproducibility, our physicians were able to distinguish between healthy subjects and patients with heart disease on the basis of QT dispersion ${ }^{1730,31}$.

\section{Study Limitations}

The most important limitation of this study was the measurement of QT dispersion. The end of repolarization can be difficult to define because of flattening of the $\mathrm{T}$ wave or the presence of a $\mathrm{U}$ wave. In the present study, when the $\mathrm{T}$ wave offset could not be identified, the lead was excluded from analysis.

The Bazett formula is commnly used to correct the QT interval for heart rate. Recently, the Fridericia formula has been considered better for correcting the QT interval when the heart rate is high. We would have liked to use the Fridericia formula in the present study, especially for high heart rates during dobutamine stress, however, the Cardio Mulyi FDX-4520 is not formatted for the Friderica formula. Hence, in this study the QT interval was corrected with the Bazett formula.

In the present study, we did not obtain control data from children because we decided that the dobutamine stress test was too invasive and that healthy children should not be subjected to such a stress test. Also, we could not obtain age-matched data. However, there were no significant differences between the control group and any of the 3 patient groups in the basic findings of heart rate and blood pressure, which strongly affect electrophysiological data. Therefore, we felt that the index of age could be ignored in this study.

\section{Conclusions}

Dobutamine-stress QT dispersion is a useful method for detectinglate anthracycline cardiotoxicity, especially for patients who cannot tolerate physical exercise. On the basis of these findings we believe that the physicians of patients with a cumulative anthracycline dose of $>150 \mathrm{mg} / \mathrm{m}^{2}$ should be aware of the possibility of subclinical anthracycline cardiotoxicity.

\section{References}

1. Bonadonna G, Monfardini S, De Lena M, FossatiBellani F, Beretta G: Phase I and II evaluation of Adriamycine (NSC 123127). Cancer Res 1970; 30: 2572-2582

2. Blum RH, Carter SK: Adriamycin, a new drug with significant clinical activity. Ann Intern Med 1974; 80: 249-259.

3. Von Hoff DD, Rozencweing M, Piccart M: The cardiotoxicity of anticancer agents. Semin Oncol 1982; 9: 23-33

4. Legha SS, Benjamin RS, Mackay B, et al:: Reduction of doxorubicin cardiotoxicity by prolonged continuous intravenous infusion. Ann Intern Med 1982; 96: 133-139. 
5. Fukazawa R, Ogawa S, Hirayama T: Early detection of anthracycline cardiotoxicity in children with acute leukemia using exercise-based echocardiography and Doppler echocardiography. Jpn Circ J 1994; 58: 625634.

6. Davy PP, Bateman J, Mulligan IP, et al.: QT interval dispersion in chronic heart failure and left ventricular hypertrophy: relation to autonomic nervous system and Holter tape abnormalities. $\mathrm{Br}$ Heart J 1994; 71: 268-273.

7. Poloniecki GY, Dickie S, Elliott PM, et al.: Is QT dispersion associated with sudden cardiac death in patients with hypertrophic cardiomyopathy? Ann Noninvasive Electrocardiol 2001; 6: 209-215.

8. Sporton SC, Taggart P, Sutton PM, et al.: Acute ischaemia: a dynamic influence on QT dispersion. Lancet 1997; 349: 306-309.

9. Paventi S, Bevilacqua U, Parafati MA, et al.: QT dispersion and early arrhythmic risk during myocardial infarction. Angiology 1999; 50: 209-215.

10. Ichkan K, Molnar J, Somberg J: Relation of left ventricular mass and QT dispersion in patients with systemic hypertension. Am J Cardiol 1997; 79: 508511.

11. Linker NJ, Colonna $P$, Kekwick CA, et al.: Assessment of QT dispersion in symptomatic patients with congenital long QT syndromes. Am J Cardiol 1992; 69: 634-638.

12. Zareba W, Moss AJ, Le Cessie S: Dispersion of ventricular repolarization and arrhythmic cardiac death in coronary artery disease. Am J Cardiol 1994; 74: 550-553.

13. Nahshoni E, Gur S, Marom S, et al.: QT dispersion in patients with social phobia. J Affective Disorders 2004; 78: 21-26.

14. Hamada H, Ohkubo $T$, Maeda M, Ogawa S: Evaluation of cardiac reserved function by high-dose dobutamine-stress echocardiography in asymptomatic anthracycline-treated survivors of childhood cancer. Pediatrics International 2006; 48: 313-320.

15. Grossman W, Jones D, McLaurin LP: Wall stress and patterns hypertrophy in the human left ventricle. J Clin Invest 1979; 56: 56-64.

16. Marsh DJ, Green LK, Wynne J, Cohn PF, Grossman W: Left ventricular end-systolic pressure-dimensio and stress-length relations in normal human subjects. Am J Cardiol 1988; 12: 426-440.

17. Kautzner J, Yi G, Camm AJ, Malik M: Short- and long-term reproducibility of QT, QTc, and QT dispersion measurement in healthy subjects. PACE 1994; 17: 928-937.

18. Linker NJ, Colonna P, Kekwick CA, Till J, Camm J, Ward DF: Assessment of QT dispersion in symptomatic patients with congenital long QT syndromes. Am J Cardiol 1992; 69: 634-638.

19. Lefrak EA, Pitha J, Rosenheim S, Gottleib JA: A clinicopathologic analysis of adriamycin cardiotoxicity. Cancer 1973; 32: 302-304.

20. Steinhertz LJ, Steinhertz PG, Tan CTC, Heller G, Murphy L: Cardiac toxicity 4 to 20 years after completing anthracycline therapy. J Am Med Assoc 1991; 266: 1672-1677.

21. Singal PK, Siveski-Iliskovic N, Hill M, Thomas TP, Li $\mathrm{T}$ : Combination therapy with probucol prevents adriamycin-induced cardiomyopathy. J Mol Cell Cardiol 1995; 27: 1055-1063.

22. Sigal PK, Iliskovic N, Li T, Kumar D: Adriamycin cardiomyopathy: pathophysiology and prevention. FASEB J 1997; 11: 931-936.

23. Doroshow JH, Locker GY, Myers CE: Enzymatic defences of the mouse heart against reactive oxygen metabolites: alterations produced by doxorubicin. J Clin Invest 1980; 65: 128-135.

24. Buja LM, Ferrans VJ, Mayer RJ, Roberts WC, Henderson ES: Cardiac ultrastructual changes induced by daunorubicin therapy. Cancer 1973; 32: 771-778.

25. Fukumi D, Uchikoba Y, Maeda M, Ogawa S: Longitudinal evaluation of anthracycline cardiotoxicity by signal-averaged electrocardiography in children with cancer. Pediatrics International 2002; 44: 134-140.

26. Horner SM, Murphy CF, Coen B, Dick DJ, Lab MJ: Sympathomimetic modulation of load-dependent changes in the action potential duration in the in situ porcine heart. Cardiovasc Res 1996; 32: 148-157.

27. Malik M, Camm AJ: Mystery of QTc interval dispersion. Am J Cardiol 1997; 79: 785-787.

28. Zabel M, Wolfgang J: Rate dependence of the QT interval and QT dispersion: comparison of atrial pacing and exercise testing. Circulation 1997; 96 (suppl I): I-325.

29. Macfarlane PW, McLaughlin SC, Rodger CR: Influence of lead selection and population on automated measurement of QT dispersion. Circulation 1998; 98: 2160-2167.

30. Nowinski K, Bergfeldt L: "Normal” response of the QT interval and QT dispersion following intravenous injection of the sodium channel blocker disopyramide: methodological aspects. Cardiovasc Drugs Ther 1995; 9: 573-580.

31. Savelieva I, Gang Y, Guo W, Hnatkova K, Malik M: Agreement and reproducibility of automatic versus manual measurement of QT interval and QT dispersion. Am J Cardiol 1998; 81: 471-477.

(Received, January 8, 2010)

(Accepted, May 29, 2010) 